\title{
Impaired $\mathrm{T}$ lymphocyte trafficking in mice deficient in an actin-nucleating protein, mDia1
}

\author{
Daiji Sakata, ${ }^{1}$ Hiroyuki Taniguchi, ${ }^{1,2}$ Shingo Yasuda, ${ }^{1,2}$ \\ Aki Adachi-Morishima, ${ }^{1}$ Yoko Hamazaki, ${ }^{3}$ Rika Nakayama, ${ }^{4}$ \\ Takashi Miki, ${ }^{1}$ Nagahiro Minato, ${ }^{3}$ and Shuh Narumiya ${ }^{1}$
}

'Department of Pharmacology, ${ }^{2}$ Horizontal Medical Research Organization, and ${ }^{3}$ Department of Immunology and Cell Biology, Kyoto University Faculty of Medicine, Kyoto 606-8501, Japan

${ }^{4}$ Laboratory for Animal Resources and Genetic Engineering, Center for Developmental Biology, RIKEN Kobe Institute, Kobe 650-0047, Japan

Trafficking of immune cells is controlled by directed migration of relevant cells toward chemotactic signals. Actin cytoskeleton undergoes continuous remodeling and serves as machinery for cell migration. The mDia family of formins and the Wiskott-Aldrich syndrome protein (WASP)-Arp2/3 system are two major actin nucleating-polymerizing systems in mammalian cells, with the former producing long straight actin filaments and the latter producing branched actin meshwork. Although much is known about the latter, the physiological functions of $\mathrm{mDia}$ proteins are unclear. We generated mice deficient in one $\mathrm{mDia}$ isoform, $\mathrm{mDia} 1$. Although $\mathrm{mDia} 1^{-/}$mice were born and developed without apparent abnormality, mDia1-l- T lymphocytes exhibited impaired trafficking to secondary lymphoid organs in vivo and showed reduced chemotaxis, little actin filament formation, and impaired polarity in response to chemotactic stimuli in vitro. Similarly, mDia1-/- thymocytes showed reduced chemotaxis and impaired egression from the thymus. These results suggest that $\mathrm{mDia} 1$ plays a distinct role in chemotaxis in T lymphocyte trafficking.

CORRESPONDENCE

Shuh Narumiya:

snaru@mfour.med.kyoto-u.ac.jp
Cell migration plays a critical role in various processes of acquired immunity, such as egression of naive $\mathrm{T}$ cells from the thymus and their homing to secondary lymphoid organs (1). Such trafficking of immune cells is controlled by their directed migration toward chemotactic signals. Actin cytoskeleton undergoes continuous remodeling and serves as machinery for cell migration (2). A critical step in this remodeling is formation of actin oligomers that serve as nuclei for further polymerization. The actin nucleation and polymerization can occur spontaneously but are facilitated by the catalysis by groups of proteins. The mDia family of formins and the WiskottAldrich syndrome protein (WASP)-Arp2/3 system are two major actin nucleating-polymerizing systems in mammalian cells, with the former producing long straight actin filaments and the latter producing branched actin meshwork (3-5).

D. Sakata, H. Taniguchi, and S. Yasuda contributed equally to this work.

The online version of this article contains supplemental material
The WASP-Arp2/3 system is under regulation by $\mathrm{Cdc} 42$ and Rac, two members of the Rho family of small GTPases, and actin meshworks induced by the WASP-Arp2/3 complex serve as an underlying structure for lammellipodia and filopodia, the structures that are induced by $\mathrm{Rac}$ and $\mathrm{Cdc} 42$, respectively (6), and promote directed cell migration $(2,5)$. The role of the WASP-Arp2/3 system in cell migration has been verified by the phenotypes of WAS patients with mutations in WASP and WASP-deficient mice, which showed defects in proliferation, differentiation, and migration of cells of the hematopoietic lineage $(7,8)$. In contrast, the mDia proteins were originally identified as Rho effectors (9). Straight actin filaments induced by $\mathrm{mDia}$ proteins are therefore used, for example, for stress fiber assembly $(10,11)$, a process regulated by Rho (6), and in contrast to the WASPArp2/3 system, their function in cell migration remains obscure. Furthermore, because functions of the mDia proteins have been studied mainly in cultured cells (3), little is known about their 
physiological roles in vivo. To address these issues, we generated mice deficient in one of the mDia proteins, mDia1 (9).

\section{RESULTS AND DISCUSSION}

We generated an mDia1-floxed strain of mice that allows deletion of the translation initiation exon, Exon 1, of mDia1 on Cre/loxP-mediated recombination (Fig. S1, A and B, available at http://www.jem.org/cgi/content/full/jem.20062647/DC1). $\mathrm{mDia}^{+/ \text {flox }}$ heterozygotes were then crossed with EIIa-Cre mice, in which Cre recombinase was expressed in the early embryo (12), to produce heterozygous $\mathrm{mDia}^{+/-}$mice, which were intercrossed to produce homozygous $\mathrm{mDia}^{-/-}$mice (Fig. S1 C). No expression of mDia1 protein was found in $\mathrm{mDia}^{-/-}$mice, whereas expression of $\mathrm{mDia} 2$ and $\mathrm{mDia} 3$ proteins was not altered (Fig. $1 \mathrm{~A}$ ). $\mathrm{mDia}^{-/-}$mice were born with an expected Mendelian ratio (Fig. S1 D). Both male and female $\mathrm{mDia}^{-/-}$mice developed without apparent abnormality and were fertile. Generated $\mathrm{mDia}^{-/-}$mice were backcrossed for more than five generations to a C57BL/6 background and used for analysis with wild-type littermates
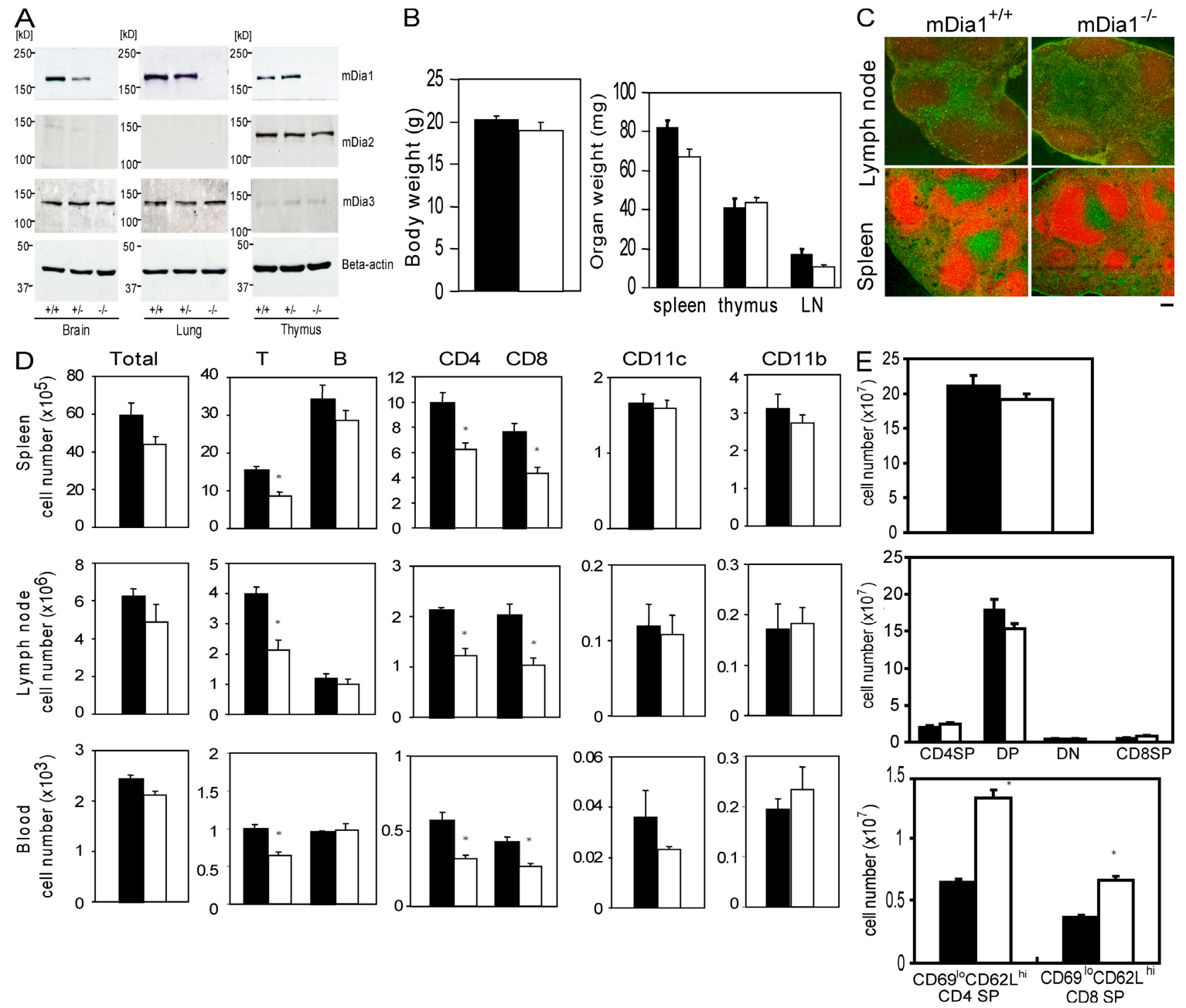

Figure 1. Decreased number of $\mathrm{T}$ cells in secondary lymphoid organs of $\mathrm{mDia} 1^{-1-}$ mice. (A) Western blot analysis. The homogenates of the brain, lung, and thymus of wild-type $(+/+)$, heterozygous $(+/-)$, and homozygous $(-/-)$ mice were subjected to immunoblot analysis for mDia1, mDia2, mDia3, and $\beta$-actin (B) Weight of the body and lymphoid organs of wild-type (shaded bars) and mDia $1^{-1-}$ (open bars) mice ( $n=3$ for each group). The experiment was performed twice with reproducible results. (C) Immunohistochemistry of the spleen and lymph node. The spleen and lymph node of $\mathrm{mDia} 1^{+/+}$and $\mathrm{mDia} 1^{-1-}$ mice were stained for Thy 1.2 (green) and B220 (red). Representative observation from samples of two mice. Bar, $100 \mu \mathrm{m}$. (D) Cell

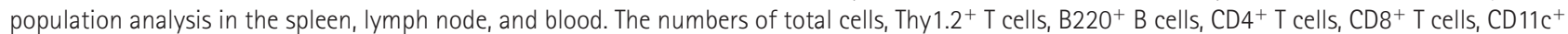
cells, and CD $11 b^{+}$cells in the spleen, lymph node, and blood were determined in mDia $1^{+/+}$(shaded bars) and mDia $1^{-1-}$ (open bars) mice. (E) Cell population analysis in the thymus. The numbers of total cells and indicated subsets of thymocytes (DN, CD4-CD8 ${ }^{-} ; \mathrm{DP}_{1} \mathrm{CD}^{+}{ }^{+} \mathrm{CD} 8^{+} ; \mathrm{CD}_{-}-\mathrm{SP}, \mathrm{CD}^{+} \mathrm{CD} 8{ }^{-} ; \mathrm{CD}^{-}$ $\left.\mathrm{SP}, \mathrm{CD}^{-} \mathrm{CD}^{+}\right)$in the thymus were determined in $\mathrm{mDia} 1^{+1+}$ (shaded bars) and $\mathrm{mDia} 1^{-1-}$ (open bars) mice. The bottom panel shows the numbers of $\mathrm{CD}_{69}{ }^{\circ} \mathrm{CD} 62 \mathrm{~L}^{\text {hi }} \mathrm{CD} 4-\mathrm{SP}$ and CD8-SP cells in the thymus of $\mathrm{mDia} 1^{+/+}$and $\mathrm{mDia} 1^{-1-}$ mice $(n=4$ for each group). Unless otherwise stated, experiments shown in $\mathrm{D}$ and $\mathrm{E}$ were performed using three mice for each group more than twice with similar results, and results from one experiment are shown. All data are shown as means \pm SEM. ${ }^{*}, \mathrm{P}<0.05$ versus the number of the corresponding population in $\mathrm{mDia} 1^{+/+}$wild-type mice. The axillary and inguinal lymph nodes were used as peripheral lymph nodes for analysis in these experiments. 
obtained from the same heterozygous mating as a control. 8-12-wk-old mice were used in subsequent analyses.

Systemic histological analysis of 8-9-wk-old $\mathrm{mDia}^{-/-}$ male and female mice ( $n=3$ each) using hematoxylin-eosin staining detected no apparent abnormality in various tissues (unpublished data). However, the wet weight of the spleen and peripheral lymph nodes (axillary and inguinal lymph nodes) tended to be lighter in $\mathrm{mDia}^{-/-}$mice, whereas that of the thymus appeared no different between the genotypes (Fig. 1 B). Immunostaining for $\mathrm{T}$ cells and $\mathrm{B}$ cells in the spleen and lymph nodes revealed normal segregation of $\mathrm{T}$ cells and B cells but less density of $\mathrm{T}$ cells in both organs of mDia1 ${ }^{-/-}$mice (Fig. 1 C). Consistently, the numbers of both CD4 and CD8 T cells were significantly reduced in the spleen and lymph nodes of $\mathrm{mDia} 1^{-/-}$mice, whereas those of $\mathrm{B}$ cells, CD $11 c^{+}$cells, and CD11 ${ }^{+}$cells were not altered (Fig. 1 D). Notably, a significant reduction $(\mathrm{P}<0.05)$ in the $\mathrm{T}$ cell number was also seen in the blood. In the thymus, although the numbers of the $\mathrm{CD} 4{ }^{-} \mathrm{CD} 8^{-}, \mathrm{CD}^{+}{ }^{+} \mathrm{CD} 8^{+}, \mathrm{CD} 4{ }^{+} \mathrm{CD} 8^{-}$, and $\mathrm{CD}^{-} \mathrm{CD}^{+}$thymocyte populations were not significantly different between wild-type and $\mathrm{mDia}^{-/-}$mice, the numbers of the $\mathrm{CD} 4^{+} \mathrm{CD} 8^{-}$and $\mathrm{CD} 4^{-} \mathrm{CD} 8^{+}$thymocytes tended to be higher in $\mathrm{mDia}^{-/-}$mice, and those of the CD69 ${ }^{\text {lo }} \mathrm{CD} 62 \mathrm{~L}^{\text {hi }} \mathrm{CD} 4$ or CD8 single-positive thymocytes significantly increased in $\mathrm{mDia}^{-/-}$mice (Fig. $1 \mathrm{E}$ ), suggesting impaired egression of mature thymocytes from the thymus in mDia1 ${ }^{-/-}$mice.

Given that trafficking of thymocytes and $\mathrm{T}$ cells is achieved by their migration to chemokines (1), we examined the response of these cells toward chemokines in vitro. The transwell assay revealed impaired chemotaxis of $\mathrm{mDia}^{-/-} \mathrm{T}$ cells toward CXC chemokine ligand (CXCL) 12 and CC chemokine ligand (CCL) 21, the two chemokines implicated in in vivo trafficking to secondary lymphoid organs (13). On the other hand, no significant impairment was found in chemotaxis of $\mathrm{mDia}^{-/-}$B cells toward CXCL12 (Fig. 2 A). Similarly, the transwell assay revealed impaired chemotaxis of $\mathrm{CD}^{+}{ }^{+} \mathrm{CD}^{+}{ }^{+}, \mathrm{CD}^{+}{ }^{+} \mathrm{CD} 8^{-}$, and $\mathrm{CD} 4{ }^{-} \mathrm{CD}^{+}$thymocytes toward CXCL12 (14) and CCL21 in the $\mathrm{mDia}^{-/-}$genotype (Fig. 2 B). To assess egression more directly, we used organ culture of the thymus. Egression of $\mathrm{CD} 4^{+} \mathrm{CD} 8^{-}$and $\mathrm{CD} 4^{-} \mathrm{CD} 8^{+}$ thymocytes from thymic lobes in response to CCL21 was significantly decreased in mDia1 deficiency (Fig. 2 C). These results indicate that impaired chemotaxis of thymocytes and $\mathrm{T}$ cells underlies the phenotype observed in $\mathrm{mDia}^{-/-}$mice. However, $\mathrm{T}$ cell trafficking to lymphoid organs in vivo may not be determined solely by the migratory activity of $\mathrm{T}$ cells but can be influenced by other factors, including the adhesive
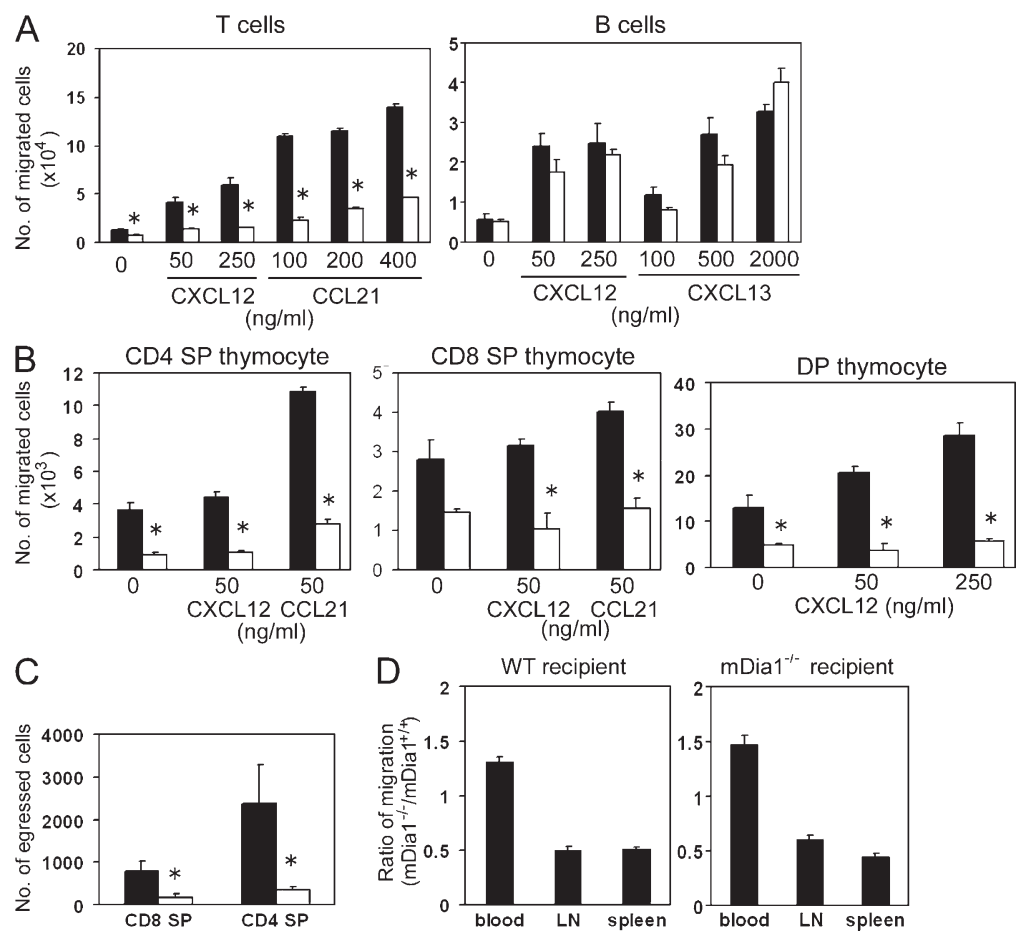

Figure 2. Impaired migration of $m D i a 1^{-l-} T$ cells and thymocytes. ( $A$ and $B$ ) Impaired chemotaxis toward chemokines in vitro. Migration of $T$ cells and $B$ cells ( $A ; n=4$ for each groups) and thymocytes ( $B ; n=3$ for each group) from mDia $1^{+1+}$ (shaded bars) and mDia $1^{-1-}$ (open bars) mice toward the indicated chemokines was examined using a transwell chamber. In B, populations of thymocytes that migrated to the bottom chamber were analyzed by flow cytometry after staining for CD4 and CD8. ${ }^{*}, P<0.05$. (C) Impaired thymocyte egression from the thymus in organ culture. Thymocytes that egressed from the thymic lobe toward CCL21 were stained for CD4 and CD8 and analyzed by flow cytometry $\left(n=3\right.$ for each group). ${ }^{*}, P<0.05$. (D) Adoptive transfer experiment. T cells were isolated from the spleen of $\mathrm{mDia} 1^{+/+}$and $\mathrm{mDia} 1^{-1-}$ mice and were labeled with different fluorescent dyes, administered to wild-type C57BL/6 mice or mDia $1^{-1-}$ recipient mice ( $n=3$ for each group). The ratios of the two populations in the blood and migrating to the spleen and the axillary and inguinal lymph nodes were analyzed after $2 \mathrm{~h}$. All data are shown as means \pm SEM. 
property of high endothelium venules in the lymphoid organs (15). To examine this issue, we performed an adoptive transfer experiment, in which we labeled $\mathrm{T}$ cells from wild-type and mDia1 ${ }^{-1-}$ mice with different fluorescent dyes and infused them i.v. into wild-type or $\mathrm{mDia}^{-/-}$recipients. The numbers of transferred cells that migrated into the spleen and lymph nodes were determined $2 \mathrm{~h}$ after the infusion. We observed that, compared with wild-type cells, only $\sim 50 \%$ of $\mathrm{mDia}^{-/-}$ $\mathrm{T}$ cells migrated into the spleen and lymph nodes and that the extent of the reduction was not different in wild-type and mDia $1^{-/-}$recipients (Fig. $\left.2 \mathrm{D}\right)$. Consistently, the higher numbers of $\mathrm{mDia}^{-/-}$cells remained in the circulation.

Given the function of $\mathrm{mDia} 1$ in actin nucleation and polymerization $(3,4)$, we next examined the cellular response of $\mathrm{mDia}^{-/-} \mathrm{T}$ cells to chemokine stimulation. The cells were initially stained with fluorescent phalloidin and subjected to flow cytometry, which revealed that the addition of CCL21 to wild-type $\mathrm{T}$ cells induced robust filamentous actin (F-actin) production in a time- and concentration-dependent manner. (Fig. $3 \mathrm{~A}$ ). In contrast, $\mathrm{T}$ cells from $\mathrm{mDia}^{-/-}$mice exhibited a substantially attenuated response at all time points measured, and the extent of attenuation was more marked at the lower chemokine concentration. Then the cells were stained for F-actin and talin. Microscopic examination of these cells revealed that wild-type $\mathrm{T}$ cells exhibited not only robust $\mathrm{F}$ actin formation but also cell polarization, and that both F-actin production and cell polarization were markedly suppressed in mDia1 ${ }^{-/-}$T cells (Fig. $3 \mathrm{~B}$ ). On the other hand, the addition of CXCL13 induced both actin filament production and polarization in $\mathrm{mDia}^{-/-} \mathrm{B}$ cells (Fig. S2, available at http://www.jem .org/cgi/content/full/jem.20062647/DC1).

Because actin polymerization is also important in $\mathrm{T}$ cell proliferation to TCR stimulation, we next examined whether $\mathrm{mDia} 1$ is involved in this process. Compared with wild-type cells, $\mathrm{mDia}^{-/-} \mathrm{T}$ cells exhibited impaired proliferation to stimulation with both anti-CD3 antibody (Fig. 4 A) and mixed lymphocyte reaction (Fig. 4 B). Thus, the loss of mDia1 affected not only $\mathrm{T}$ cell migration but also proliferation. Given that these processes are crucial in immune response, we suspected that an in vivo immune response was also impaired in $\mathrm{mDia}^{-/-}$mice. To test this issue, we subjected $\mathrm{mDia}^{-/-}$ mice to the dinitrofluorobenzene (DNFB)-induced contact hypersensitivity, a model for a $\mathrm{T}$ cell-dependent immune response. Consistent with our hypothesis, the immune response examined as the hapten-induced ear thickness was significantly impaired in $\mathrm{mDia}^{-/-}$mice (Fig. 4 C).

These results demonstrated that the deficiency of $\mathrm{mDia} 1$ significantly suppressed $(\mathrm{P}<0.05)$ the $\mathrm{T}$ cell responses, not only cell migration and polarization but also cell proliferation. Given the intricate interaction of many signaling molecules in these biological processes (6), we examined the expression and abundance of molecules other than mDia1 involved in $\mathrm{T}$ cell migration and proliferation. Flow cytometry revealed no change in the expression of the chemokine receptors CXC chemokine receptor (CXCR) 4 and CC chemokine receptor (CCR) 7 (1) in $\mathrm{mDia}^{-1-} \mathrm{T}$ cells (Fig. $5 \mathrm{~A}$ ).
Immunoblot analysis revealed that mDia1 was apparently a sole $\mathrm{mDia}$ isoform expressed in $\mathrm{T}$ cells and no compensatory expression of other isoforms in $\mathrm{mDia}^{-/-} \mathrm{T}$ cells. The $\mathrm{mDia} 1$ deficiency neither induced alteration in the amount of molecules such as RhoA, Rac1, and Cdc42 and another group of Rho effectors, ROCK 1 and 2, nor in the amount of the Arp2/3 subunit 34. However, substantial suppression was found in the
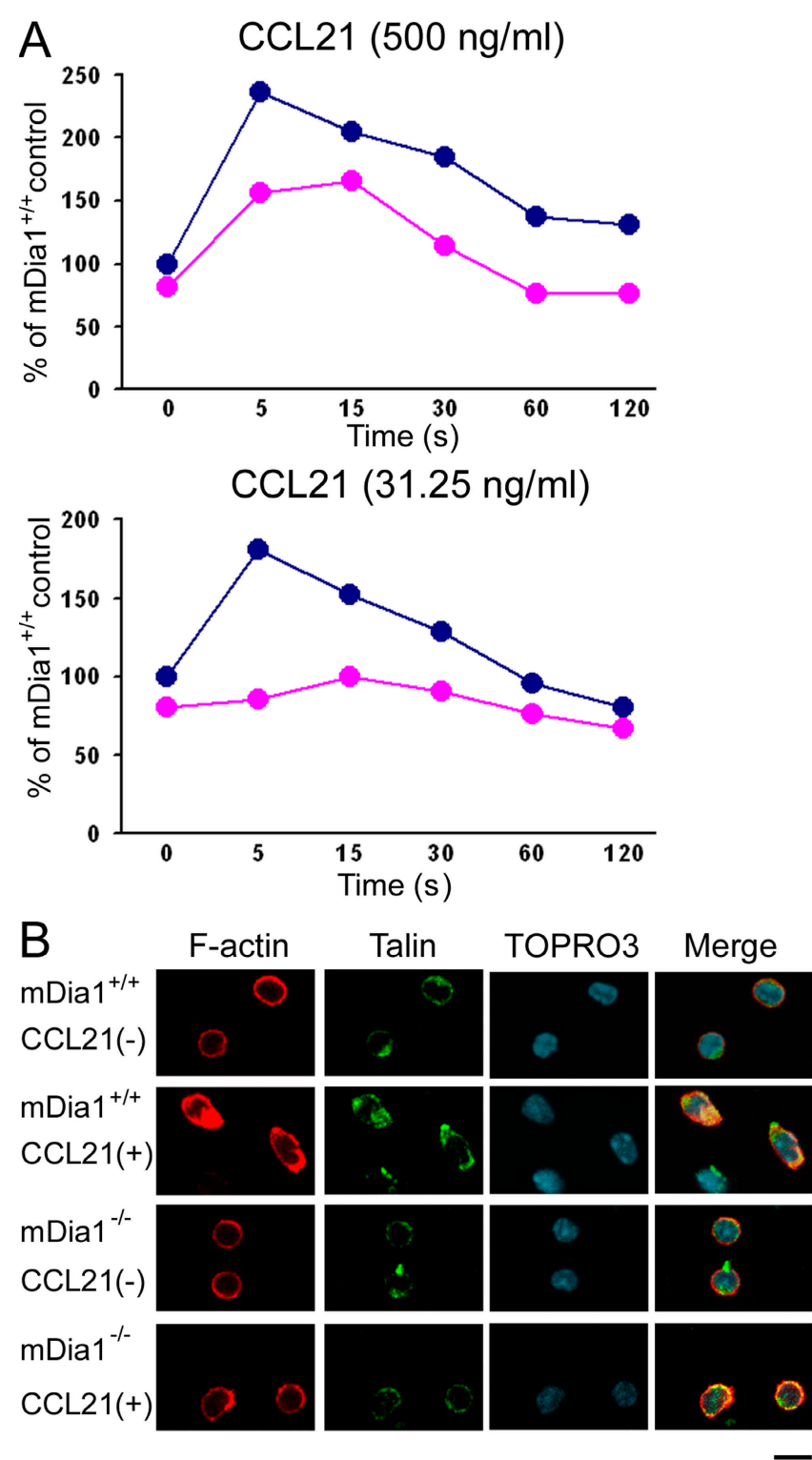

Figure 3. Impaired chemokine-induced actin polymerization and polarization of $\mathrm{mDia} 1^{-1-} \mathrm{T}$ cells. (A) F-actin production to chemokine stimulation. T cells from $\mathrm{mDia} 1^{+/+}$(blue line) and $\mathrm{mDia} 1^{-1-}$ (red line) mice were stimulated with two concentrations of CCL21 for the indicated times, stained with Oregon green-phalloidin, and analyzed by flow cytometry. Mean fluorescence intensity of the entire cell population was determined for each group and is shown with that of unstimulated mDia $1^{+/+}$cells as 100\%. (B) Impaired chemokine responses of mDia $1^{-1-} T$ cells. T cells from $\mathrm{mDia} 1^{+/+}$and $\mathrm{mDia} 1^{-1-}$ mice were stimulated with or without CCL21 and stained for talin, F-actin, and DNA, as indicated. Bar, $10 \mu \mathrm{m}$. 

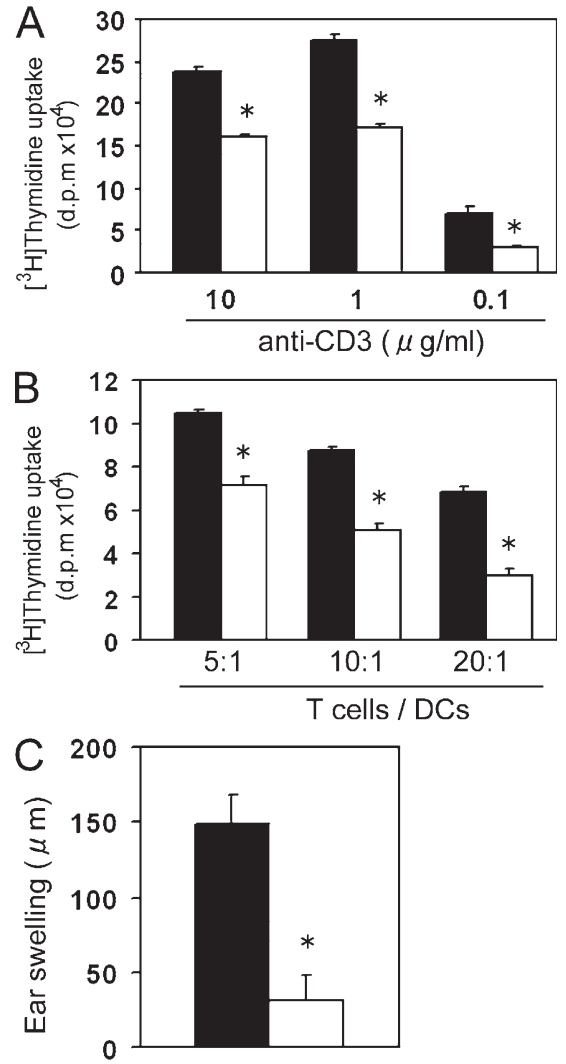

Figure 4. Impaired immune responses of $m D i a 1^{-l-} T$ cells. (A and $\left.B\right)$ Impaired proliferation of $\mathrm{mDia} 1^{-1-} \mathrm{T}$ cell. T cells from mDia $1^{+/+}$(shaded bars) and $\mathrm{mDia}^{-1-}$ (open bars) mice were cultured with plate-bound anti-CD3 antibody for $48 \mathrm{~h}(\mathrm{~A})$ or with $\mathrm{CD}_{11 \mathrm{c}^{+}}$dendritic cells for $72 \mathrm{~h}$ (B). Cell proliferation was determined by $\left[{ }^{3} \mathrm{H}\right]$ thymidine uptake. (C) Impaired contact hypersensitivity of mDia $1^{-1-}$ mice. mDia $1^{+/+}$(shaded bars) and mDia $1^{-1-}$ (open bars) mice were subjected to the DNFB-induced contact hypersensitivity, and ear thickness was measured. All data are shown as means \pm SEM.

amount of WASP in $\mathrm{mDia}^{-/-} \mathrm{T}$ cells (Fig. 5 B). Comparison with dilutions of wild-type cell lysates suggests that the WASP amount in $\mathrm{mDia}^{-/-}$cells was $\sim 25 \%$ of that in wild-type cells. In contrast to these findings, RT-PCR analysis revealed that similar amounts of WASP transcript were present in wild-type and $\mathrm{mDia}^{-/-}$cells (Fig. S3, available at http://www.jem.org/ cgi/content/full/jem.20062647/DC1). We therefore treated wild-type and $\mathrm{mDia}^{-/-} \mathrm{T}$ cells with cycloheximide and compared the rate of disappearance of WASP in the two genotypes of cells by immunoblot analysis. We found that the amount of WASP decreased more quickly in $\mathrm{mDia}^{-/-} \mathrm{T}$ cells than in wild-type cells with half-lives of $\sim 6$ and $11 \mathrm{~h}$, respectively (Fig. 5 C). To examine a mechanism for accelerated WASP degradation, we next examined the effects of a poteasome inhibitor, MG132. The addition of MG132 concentration dependently restored the amount of WASP in $\mathrm{mDia} 1^{-/-} \mathrm{T}$ cells, which was doubled by incubation with $20 \mu \mathrm{M}$ MG132 for $4 \mathrm{~h}$. On the contrary, MG132 had no effect on WASP amounts in wild-type cells (Fig. 5 D). Thus, WASP appears to be degraded via a ubiquitin-proteasome pathway in the absence of $\mathrm{mDia}$. Because WASP is one of the components of another major actin-nucleating-polymerizing system and is involved in the migration and proliferation of $\mathrm{T}$ cells, these findings raised a question as to whether the phenotype we observed is caused by the lack of $\mathrm{mDia} 1$ or partial depletion of WASP. To address this issue, we overexpressed WASP in wild-type and $\mathrm{mDia} 1^{-/-}$ $\mathrm{T}$ cells as an enhanced GFP (EGFP)-fusion protein to 17 and $19 \%$ of the level of endogenous WASP in wild-type and mDia1 ${ }^{-/-} \mathrm{T}$ cells, respectively. We also expressed EGFP as a control. Transfection efficiency was $\sim 5 \%$ for EGFP-WASP and $\sim 13 \%$ for EGFP, indicating that EGFP-WASP was present in transfected $\mathrm{mDia}^{-/-}$cells at the level of endogenous WASP in control cells. Cells expressing EGFP or EGFP-WASP were then subjected to the migration assay and F-actin staining. Overexpression of EGFP-WASP neither improved the migratory activity nor rescued impaired polarization and F-actin increase of $\mathrm{mDia}^{-/-}$cells (Fig. $5 \mathrm{E}$ ). These results suggest that a defect in the migration of $\mathrm{mDia} 1^{-/-} \mathrm{T}$ cells is primarily caused by the loss of mDia1 itself.

In this report, we revealed impaired trafficking of $\mathrm{T}$ lymphocytes in $\mathrm{mDia}^{-/-}$mice. The in vitro chemotaxis analysis and the adoptive transfer experiment suggest that the impairment is intrinsic to $\mathrm{mDia}^{-/-} \mathrm{T}$ cell lineage. These findings, together with impaired egression of thymocytes from the thymus in organ culture, indicate that the reduction of $\mathrm{T}$ cell density in the secondary lymphoid organs of $\mathrm{mDia}^{-/-}$mice is caused by impairment in both thymocyte egress from the thymus and T cell homing to the lymphoid tissues. Our analysis has further demonstrated impaired chemokine-induced F-actin formation and cell polarization in $\mathrm{mDia}^{-/-}$cells as a mechanism underlying the phenotype of the mDia1 deficiency. Previously, we used siRNA for mDia1 and showed that depletion of mDia1 in rat C6 glioma cells impaired their migration and polarization in vitro (16). Our present findings are consistent with those findings and suggest that the principles we found in cultured cells indeed operate in vivo and govern the behavior of lymphocytes in the body. Notably, $\mathrm{WASP}^{-/-}$mice or WAS patients or cells derived from them exhibit phenotypes partially overlapping those of $\mathrm{mDia}^{-/-}$ mice, such as decreased cellularity in the lymphoid organs and defects in $\mathrm{T}$ cell proliferation and migration $(17,18)$. Collectively, these results suggest that the two actin-nucleating systems work together to achieve lymphocyte functions, and the lack of either one cannot be complemented by the other.

In this respect, it is intriguing that WASP is depleted in the absence of $\mathrm{mDia} 1$, because this finding indicates not only functional but also physical interdependency of the two major actin-nucleating systems in the cell. Our results indicate that the WASP depletion in $\mathrm{mDia}^{-/-}$cells is caused by accelerated degradation via the ubiquitin-proteasome system. Previously, phosphorylation of neural WASP by the Src family kinases was found to render it susceptible to ubiquination and degradation (19). Furthermore, WAVE2, a WASP family protein, is stabilized by making a multiprotein complex, and depletion of any other component of that complex triggers 

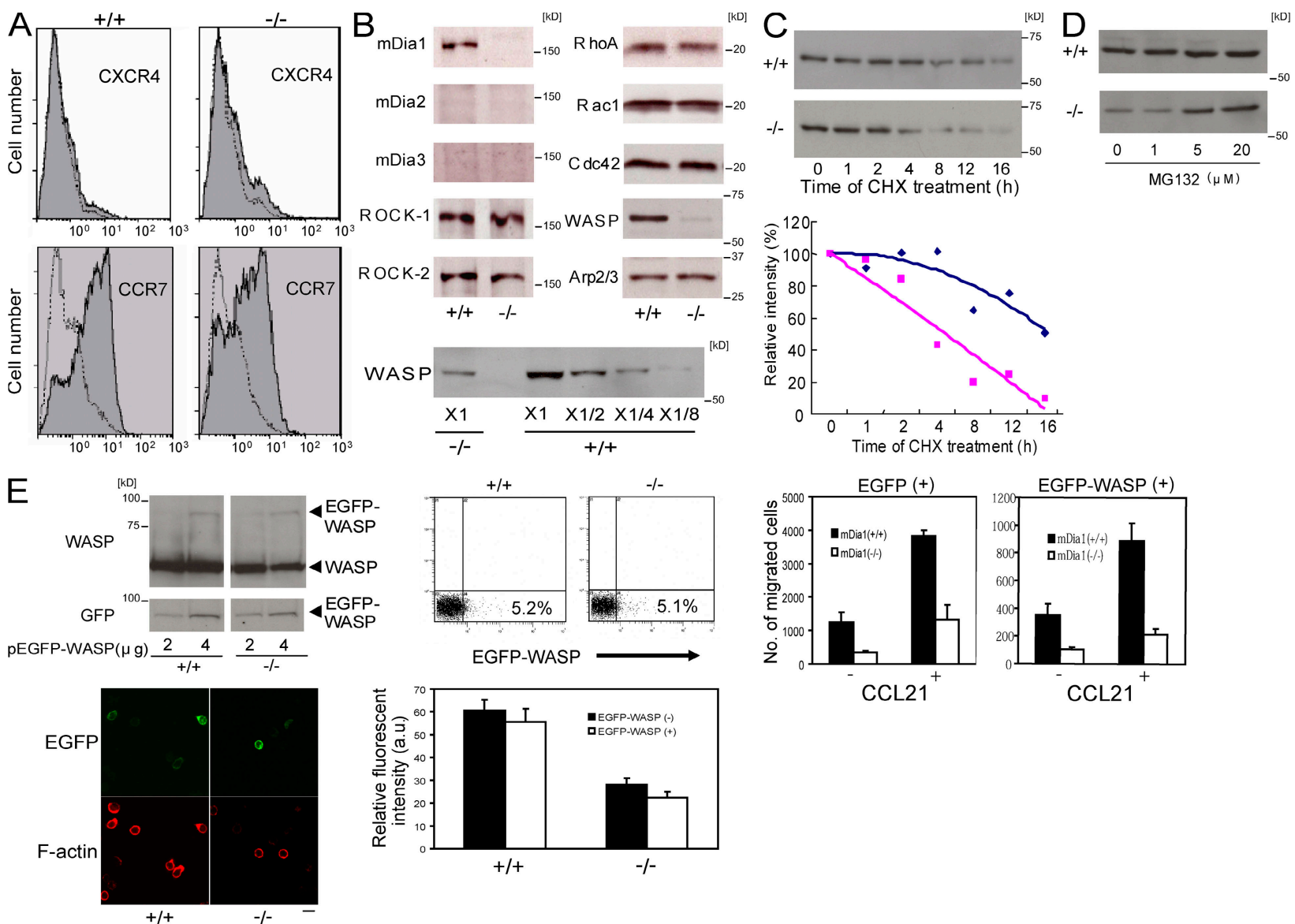

Figure 5. Analysis on signaling molecules. (A) Flow cytometry for chemokine receptor expression. $m$ Dia $1^{+/+}$and $m D i a 1^{-1-} T$ cells were stained with anti-CXCR4 or anti-CCR7 antibody (continuous line) or control antibody (dotted line) and analyzed by flow cytometry. (B) Western blot analysis of lysates of $\mathrm{mDia} 1^{-1-}$ T cells. T cells were prepared from $\mathrm{mDia} 1^{+/+}$and $\mathrm{mDia} 1^{-1-}$ mice and subjected to immunoblot analysis for $\mathrm{mDia} 1, \mathrm{mDia2}, \mathrm{mDia} 3, \mathrm{RhoA}$, Rac1, Cdc42, ROCK-1, ROCK-2, WASP, or Arp2/3 subunit 34. The amount of WASP in mDia $1^{-1-}$ T cells was examined by serial dilutions of the mDia1 ${ }^{+/+}$ lysates. (C) Degradation of WASP. T cells were treated with $10 \mu \mathrm{g} / \mathrm{ml}$ cycloheximide (CHX) for the indicated times, and cell lysates were subjected to immunoblot analysis with antibody to WASP (top). For comparison, two-fold amounts of lysates and longer color development were used for analysis of $\mathrm{mDia} 1^{-1-}$ T cells. The density of each band on the immunoblots was quantified by the densitometry and plotted (mDia $1^{+1+}$, blue line; $\mathrm{mDia} 1^{-1-}$, pink line) against incubation time with the density at $0 \mathrm{~h}$ as 100\% (right). (D) Effects of proteasome inhibitor. T cells were treated with the indicated concentrations of MG132 for $4 h$, and cell lysates were subjected to immunoblot for WASP. (E) Overexpression of WASP in mDia $1^{-1-}$ T cells. Wild-type or mDia ${ }^{-1-} T$ cells were transfected with pEGFP-WASP or pEGFP. Expression of EGFP-WASP was confirmed by Western blotting and flow cytometry (top left and top middle). Densitometry of the immunoblot of the cells transfected with $4 \mu \mathrm{g}$ pEGFP-WASP showed that EGFP-WASP was expressed at 17.4 and $18.8 \%$ of the endogenous WASP in wild-type and mDia $1^{-1-}$ cells, respectively. Wild-type and mDia $1^{-1}$ T cells transfected with $4 \mu \mathrm{g}$ of pEGFP or pEGFP-WASP were subjected to the transwell migration assay (top right) or fluorescence microscopy after staining with Texas red-phalloidin (bottom left), followed by measurement of the fluorescence intensity of F-actin staining (bottom right; $n=30$ cells each). Bar, $10 \mu \mathrm{m}$.

WAVE2 degradation via the ubiquitin-proteasome system (20). These findings indicate that mDia1 might regulate phosphorylation or complex formation of WASP in cells. In this respect, it is interesting that $\mathrm{mDia} 1$ interacts with $\mathrm{Src}$ and regulates its targeting in the cell $(16,21)$, and that mDia1 physically binds to the WASP-interacting $\mathrm{SH} 3$ protein/mDia-interacting protein that can also bind to WASP $(22,23)$. mDia1 and WASP were originally thought to act separately to induce distinct classes of actin structure. However, recent findings suggest that they work more closely and may cooperatively induce filopodia and lammellipodia (3). Thus, future analysis of the findings obtained in the present report will unravel unforeseen interrelationships between the two actin-nucleating systems that not only function cooperatively but also regulate each other's stability in the cell.

Given that the mDia family of proteins play elemental roles in actin filament dynamics, it is rather surprising that mDia $1^{-1-}$ mice exhibited relatively mild phenotypes. This is partly because of the redundancy of the mDia isoforms (3), but may also be caused by the presence of other cell-migration machinery. The latter possibility is consistent with our results on $\mathrm{B}$ cells (Fig. $2 \mathrm{~A}$ ). mDia1 is the major, almost sole, mDia isoform in B cells (unpublished data), and there is a negligible amount of WASP in B cells. Yet, there is no B cell phenotype in $\mathrm{mDia}^{-1-}$ mice, and $\mathrm{mDia} 1^{-/-} \mathrm{B}$ cells responded normally to chemotactic stimuli. In summary, our present report has 
demonstrated an essential role of mDia1 in T lymphocyte trafficking. This work should lead to a better understanding of not only immune trafficking and its defects in humans but also of various pathological processes involving cell migration.

\section{MATERIALS AND METHODS}

Mice. Mice were bred at the Institute of Laboratory Animals of Kyoto University on a $12-\mathrm{h}$ light/dark cycle under specific pathogen-free conditions. All experimental procedures were approved by the Committee on Animal Research of Kyoto University Faculty of Medicine.

Cell sorting, chemotaxis, and proliferation. Dissociated $\mathrm{T}$ cell and B cell suspensions were prepared from the spleen using an autoMACS system (Miltenyi Biotec) and were cultured as described previously (24). Chemotaxis was assayed using a transwell, as previously described (24). In brief, $3 \times 10^{5} \mathrm{~T}$ cells, B cells, or thymocytes were used, and cells that had migrated to the lower chamber after $3 \mathrm{~h}$ of incubation at $37^{\circ} \mathrm{C}$ were collected and counted by flow cytometry. For expression of EGFP-WASP, $2-4 \mu \mathrm{g}$ of pEGFP-WASP were transfected into $\mathrm{T}$ cells from wild-type or $\mathrm{mDia} 1^{-/-}$ mice using the Nucleofector system (Amaxa) with an efficiency of $\sim 5 \%$ and incubated for $18 \mathrm{~h}$ at $37^{\circ} \mathrm{C}$. The cells were subjected to Western blotting and chemotaxis assay. For thymocyte egression, a thymic lobe from new-born mice was transferred to the top chamber of a transwell, and $600 \mu \mathrm{l}$ of the medium containing $100 \mathrm{nM}$ CCL21 was added to the bottom chamber. After $24 \mathrm{~h}$ of incubation at $37^{\circ} \mathrm{C}$, cells that had egressed from the lobe and migrated to the bottom chamber were collected and analyzed by flow cytometry. For $\mathrm{T}$ cell proliferation, $\mathrm{T}$ cells were isolated from the spleen of $\mathrm{mDia}^{+/+}$and $\mathrm{mDia}^{-/-}$mice, and $2 \times 10^{5}$ cells were cultured for $48 \mathrm{~h}$ with plate-bound anti-CD3 antibody, or $2.5 \times 10^{5}$ cells were cultured with CD $11 \mathrm{c}^{+}$dendritic cells from BALB/c mice for $\left.72 \mathrm{~h} .{ }^{3} \mathrm{H}\right]$ Thymidine uptake was measured as previously described (24).

Adoptive transfer. $\mathrm{T}$ cells were isolated from the spleen of $\mathrm{mDia} 1^{+/+}$or $\mathrm{mDia} 1^{-/-}$mice and were labeled differentially with either $2 \mu \mathrm{M}$ PKH-26 red fluorescent cell linker (Sigma-Aldrich) or $1 \mu \mathrm{M}$ 5,6-carboxyfluorescein diacetate (Invitrogen) (25). After washing, $\mathrm{mDia}^{+/+}$and $\mathrm{mDia}^{-/-} \mathrm{T}$ cells were mixed in equal numbers in PBS, and $5 \times 10^{6}$ cells were i.v. injected into recipient $\mathrm{C} 57 \mathrm{BL} / 6$ or $\mathrm{mDia}^{-/-}$mice. After $2 \mathrm{~h}$, the blood, spleen, and lymph nodes were removed from the recipient mice. A cell suspension was prepared, and the numbers of cells labeled with each dye were analyzed by flow cytometry.

Western blotting. The brain, lung, and thymus were isolated from adult mice, and T cells were prepared from the spleen. These organs and cells were lysed in RIPA buffer $(20 \mathrm{mM}$ Tris-HCl, $\mathrm{pH} 7.4,150 \mathrm{mM} \mathrm{NaCl}, 2 \mathrm{mM}$ EDTA, $1 \%$ Nonidet P-40, 1\% Na deoxycholate, $0.1 \%$ SDS) containing a mixture of protease inhibitors $(10 \mu \mathrm{g} / \mathrm{ml}$ aprotin, $10 \mu \mathrm{g} / \mathrm{ml}$ leupeptin, $1 \mathrm{mM}$ PMSF) and $5 \mathrm{mM} 2$-mercaptoethanol. The lysates were boiled and subjected to SDS-PAGE, and separated proteins were transferred to nitrocellulose membranes. The membranes were probed with antibodies to $\mathrm{mDia} 1$ (Bethyl Laboratories), mDia3, RhoA, ROCK-1, WASP (Santa Cruz Biotechnology, Inc.), ROCK-2, Rac1, Cdc42 (Transduction Laboratories), Arp2/3 subunit 34 (Imgenex), $\beta$-actin (Sigma-Aldrich), GFP (MBL International Corporation), or $\mathrm{mDia} 2$. Antibody to $\mathrm{mDia} 2$ (provided by $\mathrm{Y}$. Ando, Kyoto University Faculty of Medicine, Kyoto, Japan) was raised in rabbits against a recombinant protein corresponding to Rho-binding domain of mDia2 expressed in Escherichia coli as a His-tagged protein. To examine the stability of WASP, T cells were incubated with $10 \mu \mathrm{g} / \mathrm{ml}$ cycloheximide for $0,1,2,4,8,12$, and $16 \mathrm{~h}$. The cells were subjected to Western blotting for WASP. The effects of MG132 were examined by incubating T cells with $0,1,5$, and $20 \mu \mathrm{M} \mathrm{MG}-132$ (Peptide Institute) for $4 \mathrm{~h}$.

Fluorescence microscopy. Cryostat sections were prepared from the spleen and lymph node, fixed in cold acetone for $10 \mathrm{~min}$, and stained with FITC- or PE-labeled anti-Thy1.2 or anti-B220 monoclonal antibodies. For chemokine responses, cells were cultured in the culture medium at $37^{\circ} \mathrm{C}$ overnight on poly-L-lysine-coated coverslips, and the medium was changed with the fresh medium with or without $100 \mathrm{ng} / \mathrm{ml} \mathrm{CCL21} \mathrm{(R \& D} \mathrm{Systems)}$ for T cells or $500 \mathrm{ng} / \mathrm{ml} \mathrm{CXCL13} \mathrm{(R \& D} \mathrm{Systems)} \mathrm{for} \mathrm{B} \mathrm{cells.} \mathrm{After} 10 \mathrm{~min}$, the cells were fixed with $4 \%$ paraformaldehyde in PBS, permeabilized with $0.1 \%$ Triton X-100, and stained with antibody to talin, Texas red-phalloidin, and TOPRO3. Talin was visualized by Alexa Fluor 488-labeled anti-mouse IgG monoclonal antibody. Samples were analyzed on a confocal laser scanning microscope (LSM510; Carl Zeiss MicroImaging, Inc.). Fluorescence intensity of F-actin staining with Texas red-phalloidin was determined in each cell by using MetaMorph (Universal Imaging Corp.), as previously described (16).

Flow cytometric analysis. Cell suspensions were prepared from the thymus, spleen, and lymph node and were incubated with FITC- or PE-labeled monoclonal antibody to CD4, CD8, Thy1.2, B220, CD11c, CD11b, CD62L, CD69, CXCR4, or CCR7 (29). For analysis of the CD69 $9^{\text {lo }}$ CD62 $\mathrm{L}^{\text {hi }}$ thymocyte subset, Cy5- or APC-labeled monoclonal antibody to CD4 or CD8 was used. Labeled cells were then subjected to flow cytometry. For analysis of $\mathrm{F}$-actin production, $10^{6} \mathrm{~T}$ cells were stimulated with CCL21 for various times and fixed with $4 \%$ paraformaldehyde in PBS, treated with $0.1 \%$ saponin, and stained with Oregon green-phalloidin (26).

Contact hypersensitivity. Mice were immunized by application of $25 \mu \mathrm{l}$ of $0.5 \%$ DNFB in $4: 1(\mathrm{vol} / \mathrm{vol})$ acetone/olive oil to their shaved abdomens on day 0 and were challenged on day 5 by paining the ear with $20 \mu l$ of $0.3 \%$ (wt/vol) DNFB. Ear thickness was measured $24 \mathrm{~h}$ after challenge.

Statistical analysis. All data are shown as means \pm SEM. Comparisons of two groups were analyzed using the unpaired two-tailed Student's $t$ test. $\mathrm{P}<0.05$ was considered statistically significant. The analyses were performed by Prism software (version 4; GraphPad).

Online supplemental material. Materials and methods describes the generation and breeding of mDia1-deficient mice and the RT-PCR analysis of WASP mRNA. Fig. S1 shows a diagram of the loxP-frt/Neo cassette used in the targeting vector, schematic representation of the wild-type allele, the targeting vector, the targeted allele and the knockout allele for mDia1, and a PCR genotyping and ratio of wild-type, heterozygous, and homozygous littermates. Fig. S2 shows chemokine responses of $\mathrm{mDia}^{-/-} \mathrm{B}$ cells examined by F-actin staining. Fig. S3 shows RT-PCR and real-time PCR of WASP mRNA in $\mathrm{mDia}^{+/+}$and $\mathrm{mDia} 1^{-/-} \mathrm{T}$ cells. Online supplemental material is available at http://www.jem.org/cgi/content/full/jem.20062647/DC1.

We thank S. Suetsugu (University of Tokyo, Tokyo, Japan) for pEF-BOS-GFP-WASP, Y. Ando for antibody to mDia2, T. Kinashi and K. Katagiri for advice on adoptive transfer, Y. Fukui and Y. Tanaka for advice on flow cytometry of F-actin content, and K. Nonomura, Y. Kitagawa, and T. Arai for assistance.

This work was supported in part by a Grant-in-Aid for Specially Promoted Research from the Ministry for Education, Culture, Sports, Science and Technology. The authors have no conflicting financial interests.

Submitted: 19 December 2006

Accepted: 12 July 2007

\section{REFERENCES}

1. Cyster, J.G. 2005. Chemokines, sphingosine-1-phosphate, and cell migration in secondary lymphoid organs. Annu. Rev. Immunol. 23: 127-159.

2. Ridley, A.J., M.A. Schwartz, K. Burridge, R.A. Firtel, M.H. Ginsberg, G. Borisy, J.T. Parsons, and A.R. Horwitz. 2003. Cell migration: integrating signals from front to back. Science. 302:1704-1709.

3. Faix, J., and R. Grosse. 2006. Staying in shape with formins. Dev. Cell. 10:693-706.

4. Higashida, C., T. Miyoshi, A. Fujita, F. Oceguera-Yanez, J. Monypenny, Y. Andou, S. Narumiya, and N. Watanabe. 2004. Actin polymerization-driven molecular movement of $\mathrm{mDia} 1$ in living cells. Science. 303:2007-2010. 
5. Pollard, T.D., and G.G. Borisy. 2003. Cellular motility driven by assembly and disassembly of actin filaments. Cell. 112:453-465.

6. Hall, A. 2005. Rho GTPases and the control of cell behaviour. Biochem. Soc. Trans. 33:891-895.

7. Ochs, H.D., and L.D. Notarangelo. 2005. Structure and function of the Wiskott-Aldrich syndrome protein. Curr. Opin. Hematol. 12:284-291.

8. Thrasher, A.J. 2002. WASp in immune-system organization and function. Nat. Rev. Immunol. 2:635-646.

9. Watanabe, N., P. Madaule, T. Reid, T. Ishizaki, G. Watanabe, A. Kakizuka, Y. Saito, K. Nakao, B.M. Jockusch, and S. Narumiya. 1997. p140 mDia, a mammalian homolog of Drosophila diaphanous, is a target protein for Rho small GTPase and is a ligand for profilin. EMBO J. 16:3044-3056.

10. Watanabe, N., T. Kato, A. Fujita, T. Ishizaki, and S. Narumiya. 1999. Cooperation between $\mathrm{mDia}$ and ROCK in Rho-induced actin reorganization. Nat. Cell Biol. 1:136-143.

11. Hotulainen, P., and P. Lappalainen. 2006. Stress fibers are generated by two distinct actin assembly mechanisms in motile cells. J. Cell Biol. 173:383-394.

12. Lakso, M., J.G. Pichel, J.R. Gorman, B. Sauer, Y. Okamoto, E. Lee, F.W. Alt, and H. Westphal. 1996. Efficient in vivo manipulation of mouse genomic sequences at the zygote stage. Proc. Natl. Acad. Sci. USA. 93:5860-5865.

13. Stein, J.V., and C. Nombela-Arrieta. 2005. Chemokine control of lymphocyte trafficking: a general overview. Immunology. 116:1-12.

14. Ara, T., M. Itoi, K. Kawabata, T. Egawa, K. Tokoyoda, T. Sugiyama, N. Fujii, T. Amagai, and T. Nagasawa. 2003. A role of CXC chemokine ligand $12 /$ stromal cell-derived factor-1/pre-B cell growth stimulating factor and its receptor CXCR 4 in fetal and adult $\mathrm{T}$ cell development in vivo. J. Immunol. 170:4649-4655.

15. Miyasaka, M., and T. Tanaka. 2004. Lymphocyte trafficking across high endothelial venules: dogmas and enigmas. Nat. Rev. Immunol. 4:360-370.

16. Yamana, N., Y. Arakawa, T. Nishino, K. Kurokawa, M. Tanji, J. Monypenny, T. Ishizaki, H. Bito, K. Nozaki, N. Hashimoto, et al. 2006. Rho-mDia1 pathway regulates cell polarity and focal adhesion turnover in migrating cells through mobilizing Apc and c-Src. Mol. Cell. Biol. 26:6844-6858.
17. Zhang, J., A. Shehabeldin, L.A. da Cruz, J. Butler, A.K. Somani, M McGavin, I. Kozieradzki, A.O. dos Santos, A. Nagy, S. Grinstein, et al. 1999. Antigen receptor-induced activation and cytoskeletal rearrangement are impaired in Wiskott-Aldrich syndrome protein-deficient lymphocytes. J. Exp. Med. 190:1329-1342.

18. Zicha, D., W.E. Allen, P.M. Brickell, C. Kinnon, G.A. Dunn, G.E. Jones, and A.J. Thrasher. 1998. Chemotaxis of macrophages is abolished in the Wiskott-Aldrich syndrome. Br. J. Haematol. 101:659-665.

19. Suetsugu, S., M. Hattori, H. Miki, T. Tezuka, T. Yamamoto, K. Mikoshiba, and T. Takenawa. 2002. Sustained activation of N-WASP through phosphorylation is essential for neurite extension. Dev. Cell. 3:645-658.

20. Kunda, P., G. Craig, V. Dominguez, and B. Baum. 2003. Abi, Sra1, and Kette control the stability and localization of SCAR/WAVE to regulate the formation of actin-based protrusions. Curr. Biol. 13:1867-1875.

21. Tominaga, T., E. Sahai, P. Chardin, F. McCormick, S.A. Courtneidge, and A.S. Alberts. 2000. Diaphanous-related formins bridge Rho GTPase and Src tyrosine kinase signaling. Mol. Cell. 5:13-25.

22. Meng, W., M. Numazaki, K. Takeuchi, Y. Uchibori, Y. Ando-Akatsuka, M. Tominaga, and T. Tominaga. 2004. DIP (mDia interacting protein) is a key molecule regulating $\mathrm{Rho}$ and $\mathrm{Rac}$ in a Src-dependent manner. EMBO J. 23:760-771.

23. Fukuoka, M., S. Suetsugu, H. Miki, K. Fukami, T. Endo, and T. Takenawa. 2001. A novel neural Wiskott-Aldrich syndrome protein (N-WASP) binding protein, WISH, induces Arp2/3 complex activation independent of Cdc42. J. Cell Biol. 152:471-482.

24. Kabashima, K., T. Murata, H. Tanaka, T. Matsuoka, D. Sakata, N. Yoshida, K. Katagiri, T. Kinashi, T. Tanaka, M. Miyasaka, et al. 2003. Thromboxane A2 modulates interaction of dendritic cells and $\mathrm{T}$ cells and regulates acquired immunity. Nat. Immunol. 4:694-701.

25. Katagiri, K., N. Ohnishi, K. Kabashima, T. Iyoda, N. Takeda, Y. Shinkai, K. Inaba, and T. Kinashi. 2004. Crucial functions of the Rap1 effector molecule RAPL in lymphocyte and dendritic cell trafficking. Nat. Immunol. 5:1045-1051.

26. Fukui, Y., O. Hashimoto, T. Sanui, T. Oono, H. Koga, M. Abe, A. Inayoshi, M. Noda, M. Oike, T. Shirai, and T. Sasazuki. 2001. Haematopoietic cell-specific CDM family protein DOCK2 is essential for lymphocyte migration. Nature. 412:826-831. 